\title{
\{
}

\section{La economía de la atención: del ciber-tiempo al tiempo cinemático ${ }^{1}$}

Claudio Celis Bueno²

Recibido: 07/07/2020; Aceptado: 19/08/2020

Cómo citar: Celis Bueno, C. (2020). La economía de la atención: del ciber-tiempo al tiempo cinemático. Revista Hipertextos, 8(14), pp. 59-71. DOI: https://doi.org/10.24215/23143924e019

Resumen. Este artículo examina la dimensión temporal de la economía de la atención utilizando la noción de tiempo cinemático de Bernard Stiegler. La economía de la atención es un concepto forjado dentro del campo de la economía política para explicar el creciente valor de la atención en un mundo abundante en información. Esto implica una creciente discrepancia entre la finitud del tiempo humano requerido para prestar atención y procesar la información disponible, y la velocidad inhumana a la que fluye y se acumula dicha información. El problema con esta definición de la temporalidad de la economía de la atención es que naturaliza una noción dada de tiempo humano que luego es utilizada para evaluar los efectos negativos de las tecnologías de la información. En este sentido, el tiempo humano es propuesto como un concepto privado de cualquier tipo de transformación histórica. Contrariamente a esta definición de la temporalidad de la economía de la atención, este artículo utiliza el concepto de tiempo cinemático de Bernard Stiegler para examinar cómo el tiempo humano y el ciber-tiempo se constituyen mutuamente.

Palabras clave: Bernard Stiegler, tecnicidad originaria, temporalidad, información, capital

\section{The Attention Economy: from Cyber-Time to Cinematic Time}

Abstract. This article explores the temporal dimension of the attention economy through Bernard Stiegler's notion of cinematic time. The attention economy is a concept forged within the field of political economy to explain the growing value of attention in an information-rich world. This implies a growing discrepancy between the finite nature of human time required to pay attention to and process the available information, and the inhuman speed at which that information flows and accumulates. The problem with this definition of the temporality of the attention economy is that it naturalizes a given notion of human time that is then used to evaluate the negative effects of information technologies. In this sense, human time is proposed as a concept devoid of any kind of historical transformation. Contrary

${ }^{1}$ Capítulo publicado originalmente en inglés bajo el título "The Attention Economy: from cyber-time to cinematic time” en el libro Memories of the Future: On Countervision, editado por Stephen Wilson y Deborah Jaffé (Peter Lang, 2017).

2 Académico e investigador del Instituto de Humanidades de la Universidad Academia de Humanismo Cristiano, Santiago, Chile. Contacto: ccelis@academia.cl 
to this definition of the temporality of the attention economy, this article uses Bernard Stiegler's concept of cinematic time to examine how human time and cyber-time mutually constitute each other.

Keywords: Bernard Stiegler, originary technicity, temporality, information, capital

\section{A economia da atenção: do ciber-tempo ao tempo cinematográfico}

Resumo. Este artigo explora a dimensão temporal da economia da atenção por meio da noção de tempo cinematográfico de Bernard Stiegler. A economia da atenção é um conceito forjado no campo da economia política para explicar o valor crescente da atenção em um mundo rico em informações. Isso implica em uma discrepância crescente entre a natureza finita do tempo humano necessário para prestar atenção e processar a informação disponível e a velocidade desumana com que essa informação flui e se acumula. O problema com essa definição da temporalidade da economia da atenção é que ela naturaliza uma dada noção de tempo humano que é então usada para avaliar os efeitos negativos das tecnologias da informação. Nesse sentido, o tempo humano é proposto como um conceito desprovido de qualquer tipo de transformação histórica. Contrariamente a esta definição de temporalidade da economia da atenção, este artigo usa o conceito de tempo cinematográfico de Bernard Stiegler para examinar como o tempo humano e o tempo cibernético se constituem mutuamente.

Palavras-chave: Bernard Stiegler, tecnicidade originária, temporalidade, informação, capital 


\section{Introducción}

El objetivo de este artículo es examinar la dimensión temporal de la economía de la atención utilizando la noción de tiempo cinemático de Bernard Stiegler (2004). La economía de la atención es un concepto forjado dentro del campo de la economía política para explicar el creciente valor de la atención en un mundo abundante en información (Simon, 1971). El hecho de que la información esté adquiriendo un papel tan crucial para el proceso productivo implica que la atención necesaria para procesarla se está convirtiendo rápidamente en un recurso escaso. $\mathrm{Al}$ mismo tiempo, parece haber una creciente discrepancia entre la finitud del tiempo humano requerido para prestar atención y procesar la información disponible, y la velocidad inhumana a la que fluye y se acumula dicha información. Esta discrepancia ha llevado a algunos autores (Christian Marazzi, 2003; Franco Berardi, 2014; y Jonathan Crary, 2013; entre otros) a argumentar que la temporalidad de la economía de la atención se caracteriza por la relación asimétrica entre el tiempo humano y el ciber-tiempo. El problema con esta definición de la temporalidad de la economía de la atención es que naturaliza una noción dada de tiempo humano que luego es utilizada para evaluar los efectos negativos de las tecnologías de la información. En este sentido, el tiempo humano es propuesto como un concepto privado de cualquier tipo de transformación histórica. Contrariamente a esta definición de la temporalidad de la economía de la atención, este artículo utiliza el concepto de tiempo cinemático de Bernard Stiegler (2004) para examinar cómo el tiempo humano y el ciber-tiempo se constituyen mutuamente. ${ }^{3}$

\section{Ciber-tiempo}

Desde su formulación original por parte de Herbert A. Simon, la cuestión del tiempo ha sido una preocupación central tanto para los apologistas como para los críticos de la economía de la atención. Simon argumenta que, para asignar eficientemente la atención, se deben encontrar formas de medir las cantidades de dicho recurso escaso (Simon, 1971). Una forma de hacerlo, sugiere, es medir el tiempo de atención necesario para el consumo de un mensaje dado: "la escasez de atención en un mundo rico en información, nos dice, se medirá por el tiempo, en minutos o en horas, digamos, de un ejecutivo humano" (Simon, 1971). Para Simon, esto es posible porque la atención humana es esencialmente una actividad en serie, es decir, si atendemos a una cosa, no podemos, simultáneamente, atender a otra. A este respecto, incluso la

\footnotetext{
3 Es útil tener en cuenta que la definición de Stiegler de tiempo cinemático rompe con la comprensión representacional de la relación entre imágenes y temporalidad. Tradicionalmente, la relación entre imágenes y temporalidad se ha reducido a la esfera de la representación: ya sea cine o fotografía, una imagen se concibe como un soporte de memoria externa que fija un momento fugaz, es decir, representa un fragmento de tiempo específico (ver Bazin, 1990; y Doane, 2016). Por el contrario, Stiegler lee el tiempo y las imágenes desde una perspectiva más allá de la representación. Como se mostrará, para Stiegler, las imágenes no representan el tiempo; más bien, producen una temporalidad dada que da forma a la experiencia temporal del sujeto. En este sentido, el tratamiento no representacional de Stiegler del tiempo cinemático podría entenderse dentro de la tradición bastante pequeña de la fenomenología del cine. Casebier (1991), Sobchack (1992), Susan Buck-Morss (1994) y Shaw (2008) constituyen algunos de los pocos intentos de construir una fenomenología del cine. El uso de Stiegler del concepto de objeto temporal de Husserl parece ubicarlo dentro de esta tradición. Sin embargo, su lectura particular de Husserl (influenciada por la propia lectura de Derrida) también marca una ruptura importante con el concepto fenomenológico de subjetividad.
} 
multitarea [multi-tasking] contemporánea debe verse como el intercambio de tiempo de atención lineal entre varios objetos. Como lo expresa Simon,

[a pesar del hecho de que los usuarios modernos de tareas múltiples parecen capaces] de atender cien cosas a la vez; realmente no lo hacen, por supuesto. Más bien, comparten su tiempo y atención entre estas cien cosas. Por lo tanto, la medida de capacidad de atención que propongo funcionará para sistemas de tiempo compartido, así como para sistemas informáticos más convencionales de seres humanos. Una organización que emplea a muchas personas también se puede ver como un sistema de tiempo compartido, y su problema de asignación de atención debe ser tratado de acuerdo a ello (Simon, 1971).

El tiempo de atención se trata como un recurso escaso a partir de una abundancia de información y conocimiento que ahora gobierna el proceso de producción. Sin embargo, desde una perspectiva marxista, se podría argumentar que esta discrepancia entre la abundancia de información y la escasez de atención se basa en un proceso de aceleración inherente al modo de producción capitalista. Según Marx, el capitalismo es esa "contradicción" que emplea la tecnología para "reducir a un mínimo el tiempo de trabajo necesario" y al mismo tiempo plantea el tiempo de trabajo como la "única medida y fuente de la riqueza" (Marx, 2009, p. 229). Para contrarrestar la tendencia a la crisis inherente a esta contradicción, el capitalismo se ve obligado a reducir constantemente la cantidad de tiempo de trabajo necesario y aumentar la cantidad de plusvalía relativa. Esta tendencia impulsa al capitalismo hacia un proceso continuo de aceleración. En palabras de Franco Berardi, "cuando Marx alude a la plusvalía relativa, está refiriéndose a procesos de aceleración [...] si se quiere conseguir un incremento en la productividad es preciso acelerar el tiempo de trabajo" (2014, p. 81).

En el caso específico de la economía de la atención, la lógica de la aceleración se ha empleado para explicar la creciente discrepancia entre el tiempo de atención humana y el tiempo inhumano de los flujos de información. Berardi argumenta que cuando el trabajo se vuelve cognitivo, la aceleración depende menos del trabajo manual y más de la velocidad de la esfera de información. El problema, señala, es que el cerebro funciona "en el tiempo" y necesita tiempo para prestar atención y comprender [...], y por ello la "cantidad de tiempo disponible de atención no es ilimitada porque la atención no se puede acelerar más allá de ciertos límites” (Berardi, 2014, p. 82). Por lo tanto, concluye Berardi, en la economía de la atención, la velocidad y la aceleración están vinculadas a la relación entre la cantidad de bienes semióticos que se producen y la cantidad de tiempo de atención que se dispone (Berardi, 2014, pp. 81-82). Desde esta perspectiva, la temporalidad de la economía de la atención aparece como resultado de una relación asimétrica entre la temporalidad limitada del sujeto (o tiempo humano) y la temporalidad relativamente ilimitada de los flujos de información (o tiempo del ciber-espacio). Berardi lo resume de la siguiente manera:

[El problema esencial con la economía de la atención es que] los ritmos de la mutación tecnológica son mucho más rápidos que los de la mutación mental. Por lo tanto, la expansión del ciberespacio es inconmensurablemente más rápida que la capacidad del cerebro humano para expandirse y adaptarse. Podemos aumentar el tiempo que un organismo está expuesto a la información, pero la experiencia no puede intensificarse más allá de cierto límite. La aceleración provoca un empobrecimiento de la experiencia, dado que 
estamos expuestos a una creciente masa de estímulos que no podemos digerir en los modos intensivos de disfrute y conocimiento (Berardi, 2009, p. 89).

Como ya se anticipó, el principal problema con esta comprensión de la temporalidad de la economía de la atención es que naturaliza una concepción dada de la temporalidad de la atención humana y la opone a la de los flujos técnicos de información. Dicho de otra manera, al definir la temporalidad de la economía de la atención a través de la discrepancia entre un tiempo humano subjetivo y el ciber-tiempo de la esfera de información, Berardi reproduce una oposición entre la temporalidad viva de la experiencia humana y el tiempo muerto de las máquinas técnicas. Al hacerlo, Berardi universaliza el tiempo humano abstracto como un punto de vista externo y ahistórico desde el cual desarrollar una crítica de la economía de la atención. Berardi opone un tiempo humano a un tiempo deshumanizante del ciber-espacio y utiliza el primero como un marco normativo desde donde criticar la rápida aceleración del segundo.

Por el contrario, el concepto de tiempo cinemático de Bernard Stiegler (2004) ofrece una nueva definición de la relación entre temporalidad y tecnología que permite romper con la oposición entre el tiempo humano y el ciber-tiempo. Según Stiegler, el tiempo de vida y la tecnología están relacionados entre sí, y se moldean mutuamente. En este sentido, no puede haber una definición universal del tiempo humano desde donde desarrollar una crítica del cibertiempo. En cambio, el concepto de tiempo cinemático de Stiegler sienta las bases para desarrollar una crítica inmanente de la temporalidad de la economía de la atención.

\section{Tiempo cinemático}

Bernard Stiegler presenta el concepto de tiempo cinematográfico en el tercer volumen de su serie de libros La técnica y el tiempo (2004). Como parte de esta serie, el concepto de tiempo cinemático debe ser comprendido como parte de la teoría de "tecnicidad originaria" desarrollada por Stiegler. Stiegler afirma que la tecnología no es externa a la constitución humana (es decir, una herramienta que un individuo totalmente constituido utiliza para un objetivo específico), sino que los humanos están constituidos por la tecnología a través de un proceso continuo de exteriorización (o gramatización). ${ }^{4}$ Además, la teoría de la tecnicidad originaria implica una teoría de la temporalidad según la cual nuestra capacidad interna de temporalizar (experimentar el mundo como un flujo temporal) está conformada por este proceso continuo de exteriorización. Según Arthur Bradley,
la filosofía de la tecnología de Stiegler se basa en la audaz afirmación según la cual existe una relación esencial entre la técnica y el tiempo: lo que la fenomenología llama la capacidad humana de "temporalizar", organizar su experiencia del flujo del tiempo, se constituye, en lugar de simplemente complementarse por, prótesis mnemotécnicas [...] Para Stiegler, la filosofía occidental desde la metafísica griega hasta la fenomenología moderna constituye una serie de oposiciones entre la técnica y el tiempo que relega a la primera a una posición puramente incidental o complementaria. A la manera de pensar de Stiegler, por el contrario,

\footnotetext{
4 Según Arthur Bradley (2011), el término “tecnicidad originaria” fue acuñado por Jacques Derrida como un elemento crucial de su "deconstrucción de la metafísica occidental de la presencia". En este sentido, argumenta, el tratamiento de la tecnicidad de Stiegler es una continuación de la idea de Derrida según la cual el origen de la temporalidad reside en un proceso original de "gramatización" o "exteriorización".
} 
ya no podemos oponer la técnica y el tiempo: todo el tiempo [...] es siempre ya técnico. (Bradley, 2011, p. 120)

Del mismo modo, Patrick Crogan explica que, para Stiegler, el tiempo se constituye en y a través de un proceso de exteriorización técnica:

Tanto la anticipación del futuro como la memoria de un pasado no vivido son posibles gracias al advenimiento de la herramienta. La herramienta es una especie de memoria externa de las experiencias y conocimientos de quienes la idearon, refinaron y transmitieron. Usar una herramienta es anticipar el futuro resultante de su despliegue, un futuro heredado de esas vidas pasadas de las cuales no otra cosa que su exteriorización cristalizada. (Crogan, 2006, p. 40)

Dicho de otra manera, la técnica es un soporte de memoria externa que determina nuestra experiencia temporal interna, borrando así los límites entre el interior y el exterior, entre una experiencia viva del tiempo y la memoria técnica, muerta.

El concepto de tiempo cinemático debe entenderse como parte de esta relación más amplia entre la técnica y el tiempo. En este sentido, el tiempo cinemático presupone una interrelación entre las imágenes (como soporte externo de memoria técnica) y nuestra capacidad humana para experimentar estas imágenes temporalmente. Stiegler emplea un concepto muy amplio de cine que incluye cualquier conjunto de imágenes en movimiento (por ejemplo, cine, televisión, video analógico y digital, etc.). En consecuencia, su análisis se aplica a cualquier dispositivo en el que estén contenidas estas imágenes en movimiento (es decir, no solo pantallas de cine, sino también televisores, teléfonos inteligentes, pantallas de computadora, tabletas, carteles callejeros, etc.). Esta comprensión del tiempo cinematográfico es importante para un análisis de la temporalidad de la economía de la atención. Como se mencionó anteriormente, la temporalidad de la economía de la atención a menudo se entiende como el resultado de una relación asimétrica entre la temporalidad limitada del sujeto (o usuario) y la temporalidad ilimitada de los flujos de información (o ciber-tiempo). Como dice Berardi, la atención es una función cerebral que requiere tiempo (y no puede, por lo tanto, "ser acelerada infinitamente"). El problema con esta concepción es que naturaliza una noción dada del tiempo humano, no logrando así comprender la interconexión entre la temporalidad del sujeto y las transformaciones históricas, técnicas y sociales que han hecho posible la economía de la atención. En otras palabras, esta comprensión reproduce lo que Stiegler dice ser el rasgo común de la metafísica occidental, es decir, la oposición entre un "tiempo psíquico vivo" y una "memoria técnica muerta" (Stiegler, 2006, p. 23).

Por el contrario, la teoría del tiempo cinemático de Stiegler intenta repensar la memoria como un proceso de gramatización en el que la memoria viva y la memoria muerta se vinculan constitutivamente (Stiegler, 2006, p. 23). Al plantear la memoria externa como “original”, Stiegler afirma que vivir la memoria psíquica es el resultado de un proceso de organización temporal en el que la memoria técnica muerta juega un papel determinante. Con esta novedosa teoría del tiempo, Stiegler introduce un importante marco conceptual desde el cual reflexionar sobre la temporalidad de la economía de la atención. Al identificar una relación interna entre imágenes y tiempo, Stiegler tiene como objetivo mostrar que la experiencia temporal del sujeto está constantemente formada por superficies externas de inscripción que funcionan como soportes 
de memoria externa. La noción de Stiegler de tiempo cinemático rompe con la oposición entre un tiempo natural y subjetivo y un tiempo de la información (o ciber-tiempo), presentando el primero como el resultado de un proceso interminable de exteriorización en el que las transformaciones históricas de las superficies de inscripción constantemente modifican la organización temporal de la conciencia. Con ello, Stiegler allana el camino hacia la construcción de una perspectiva alternativa (inmanente) para comprender la temporalidad de la economía de la atención.

\section{Híper-atención e industrialización del tiempo}

En un artículo que aborda directamente el tema de la economía de la atención, Stiegler (2012) sugiere que la atención no debe entenderse como una capacidad humana natural, sino como un modo de relación con el mundo determinado técnica e históricamente. Retomando su noción de tiempo cinemático, Stiegler afirma que cada modo de atención es el resultado de las superficies de exteriorización técnica que lo constituyen. Más aún, Stiegler recurre a los conceptos de "atención profunda" e "híper-atención" para explicar cómo las tecnologías digitales y los medios de comunicación globalizados han transformado nuestra experiencia atencional. ${ }^{5}$ Mientras que la atención profunda (lo que Stiegler llama la "forma atencional literata") corresponde al dominio de la palabra escrita, la híper-atención define las nuevas "formas atencionales" que han surgido en la era de las tecnologías digitales y los medios de comunicación globales (Stiegler, 2012, p. 8). La invención de la prensa moderna y la jerarquía del libro como fuente privilegiada de conocimiento generaron una forma muy específica de prestar atención que definió a la cultura occidental durante un largo período de su historia moderna. Sin embargo, durante el siglo XX, la aparición de "objetos temporales audiovisuales" (como el cine, la televisión y los medios digitales) generó un cambio de esta forma dominante de atención que implicó un proceso de híper-industrialización (Stiegler, 2012, p. 5). Esto inaugura una industrialización sistemática de la conciencia que se torna un obstáculo para el proceso de individualización en el que consiste dicha conciencia (Stiegler, 2004).

En cuanto a la experiencia temporal, esta industrialización genera un estado homogéneo de "tiempo real" en el que millones de conciencias consumen simultáneamente y a escala global los mismos "objetos temporales técnicos" (Stiegler, 2004, p. 47). Dado que el soporte de la memoria externa juega un papel decisivo para la constitución de la experiencia temporal, Stiegler sugiere que la industrialización de los objetos temporales crea una "híper-sincronización del tiempo de la conciencia" (Stiegler, 2011a, p. 57). Dicho de otra manera, el cambio de una profunda "forma atencional literata" basada en la palabra escrita como su principal tecnología de exteriorización hacia una híper-atención gobernada por los medios de comunicación digitales y la programación

\footnotetext{
5 Stiegler toma los conceptos de atención profunda e híper-atención de la autora Katherine Hayles (2007) para ilustrar la transformación de la atención causada por las tecnologías digitales. Para Hayles, actualmente se está produciendo una división generacional. Esta división se puede identificar en el cambio en los estilos cognitivos de lo que ella llama atención profunda hacia las nuevas formas de híper-atención. Hayles escribe: "La atención profunda, el estilo cognitivo tradicionalmente asociado con las humanidades, se caracteriza por concentrarse en un solo objeto durante largos períodos (digamos, una novela de Dickens), ignorar los estímulos externos mientras se realiza esta tarea, prefiriendo un solo flujo de información, y teniendo una alta tolerancia para un tiempo de enfoque prolongado. La híper-atención se caracteriza por cambiar rápidamente el enfoque entre diferentes tareas, prefiriendo múltiples flujos de información, buscando un alto nivel de estimulación y una baja tolerancia al aburrimiento" (Hayles, 2007).
} 
"en tiempo real" a nivel planetario, crea una homogeneización de la temporalidad (Stiegler, 2012, p. 13). Según la lectura que Arthur Bradley realiza de Stiegler, "el capitalismo contemporáneo estaría generando una híper-industrialización de la memoria, los objetos temporales y la conciencia: la capacidad humana de temporalizar, en sí misma inherentemente técnica, está ahora sujeta a un dominio tecno-económico de apropiación que no tiene paralelo en la historia" (Bradley, 2011, p. 121). Esto es más evidente en el caso de los objetos temporales "en tiempo real" (fenómeno presentado por la industria globalizada de cine y televisión), que "colapsan la compleja temporalización humano-técnica del tiempo en un tiempo presente sintético sin fin que solo puede consumirse pasivamente y de manera acrítica" (Bradley, 2011, p. 123). Del mismo modo, Patrick Crogan sugiere que los objetos temporales "en tiempo real" constituyen una proporción cada vez mayor de la experiencia de los individuos en la era moderna, otorgándole a estos objetos temporales un rol cada vez más protagónico en la producción de la experiencia temporal humana que define el "estar en el mundo" de dichos individuos (Crogan, 2006, p. 45).

Para Stiegler, esto conlleva profundas consecuencias políticas. En términos concretos, la emergencia del "tiempo real" da lugar a un proceso de desindividuación caracterizado por "la alienación, la coerción, la dependencia, la sumisión, el cortocircuito y, finalmente, por una proletarización de la individualización psíquica" (Stiegler, 2012, p. 10). En otras palabras, la homogeneización de la temporalidad amenaza los procesos de singularización que determinan el deseo individual (Stiegler, 2011a, p. 58). Desde esta perspectiva, la pérdida de la individualización representa "la ruina del narcisismo" (es decir, la ruina de nuestra capacidad de desear como individuos reflexivos) y estaría, a su vez, conduciendo a la sociedad contemporánea al "desorden político y económico" (Stiegler, 2011a, pp. 58-59). ${ }^{6}$

Stiegler habla del proceso de industrialización de la conciencia en el mismo tono que Adorno y Horkheimer hablaron de la industria cultural en su Dialéctica de la Ilustración (1998). De hecho, Stiegler se refiere explícitamente a la crítica de Adorno y Horkheimer de la industria cultural para definir lo que él llama la "llegada inminente" de una "catástrofe espiritual” (Stiegler, 2004, p. 55). Sin embargo, Stiegler sostiene que Adorno y Horkheimer no desarrollan la crítica de la industria cultural hasta sus últimas consecuencias, precisamente porque todavía confiaban en la oposición tradicional entre técnica y temporalidad (Stiegler, 2011a, p. 39). Por el contrario, Stiegler afirma que solo al comprender la relación interna entre técnica y temporalidad será posible extraer todas las consecuencias generadas por la masificación de objetos temporales industriales a nivel planetario.

\section{Del ciber-tiempo al tiempo cinemático}

Se ha mencionado más arriba que la teoría de la tecnicidad originaria de Stielger intenta repensar la oposición entre la memoria técnica muerta y la memoria psíquica viva. En este sentido, la teoría del tiempo de Stiegler puede usarse para desafiar la presuposición básica de la teoría del

\footnotetext{
6 Para Stiegler (2011a), más que una patología, "el narcisismo condiciona la psique, el deseo y la singularidad” (p. 59). Al mismo tiempo, la híper-sincronización de la conciencia "conduce a la pérdida de la individualización", la cual es clave para el desarrollo del deseo individual: "solo puedo desear la singularidad de algo en la medida en que esta cosa sea el espejo de la singularidad que yo soy" (p. 59). En su proceso de "normalización", el capitalismo está socavando su propia fuerza impulsora: "La industria cultural y el marketing se esfuerzan por desarrollar el deseo por consumir, pero con ello no hacen sino fortalecer una pulsión de muerte detrás del fenómeno compulsivo de la repetición. De esta manera frustran la pulsión de vida. En este sentido, y dado que el deseo es esencial para el consumo capitalista, este proceso no puede sino volverse autodestructivo" (p. 59).
} 
valor-trabajo de Marx. Para Marx, solo el trabajo vivo es productivo de valor. Las máquinas, por el contrario, producen valor solo en la medida en que reducen la cantidad de tiempo de trabajo vivo necesario y, por lo tanto, aumentan la cantidad de plusvalía producida por el trabajo y apropiada por el capital. Para Stiegler, la distinción entre trabajo vivo y maquinaria reproduce una definición metafísica de tecnología que opone el tiempo vivo a la memoria técnica muerta. Stiegler desafía esta oposición, argumentando que el tiempo vivo es el resultado de un proceso continuo de exteriorización. Esto significa que la tecnología constantemente da forma al tiempo psíquico vivo. En términos marxistas, se puede decir que el desarrollo técnico de los poderes productivos de una sociedad dada opera como una superficie de inscripción que constantemente da forma al tiempo vivo del trabajo humano. Desde esta perspectiva, la crítica de Stiegler a la separación entre el tiempo vivo y la memoria muerta contribuye a una reinterpretación de la distinción de Marx entre capital fijo y trabajo vivo que es más adecuada para el contexto específico del postfordismo. ${ }^{7} \mathrm{Al}$ mismo tiempo, el concepto de tiempo cinemático de Stiegler permite revelar la obsolescencia de la categoría de tiempo de trabajo como única fuente y medida de valor en un contexto postindustrial.

A partir de lo anterior es posible sostener que la noción de Stiegler de tiempo cinemático permite reinterpretar la temporalidad de la economía de la atención más allá de la oposición entre el tiempo humano y el ciber-tiempo. Para Stiegler, no existe una distinción esencial entre el tiempo psíquico vivo y la memoria técnica muerta. Esto significa que la economía de la atención no implica un choque entre un tiempo humano y uno técnico. Por el contrario, el carácter técnico de la temporalidad discutido anteriormente implica una interdependencia entre la temporalidad de los flujos de información que componen la economía digital y las constantes transformaciones de la experiencia temporal de sus usuarios. La economía de la atención no solo acelera la experiencia temporal. Reemplaza la temporalidad lineal del trabajo abstracto que caracterizó la producción industrial con una experiencia permanente de "tiempo real". El paso del capitalismo industrial al postindustrial puede leerse como el cambio de una forma de violencia (la apropiación de una parte del tiempo individual) a otra (la normalización del cibertiempo o "tiempo real" para extraer una renta de los procesos cognitivos y atencionales). Esto significa que en la economía de la atención los sujetos no solo están separados de su tiempo de trabajo y de los productos de dicho trabajo, sino que además están expuestos a una experiencia continua de simultaneidad. Este cambio hace que el tiempo individual como medida del valor de las relaciones sociales se torne obsoleto, siendo reemplazado por una "industrialización de la temporalidad" caracterizada por objetos temporales "en tiempo real".

Más aún, la experiencia del "tiempo real" de la economía de la atención afecta directamente la constitución del deseo individual que regula el consumo capitalista. Según Stiegler, el proceso de individuación que define el deseo humano depende, al igual que los procesos de temporalización, de los soportes externos de memoria "muerta" (Stiegler, 2006, p. 39). Por esta razón, una homogeneización de las superficies de exteriorización genera una normalización de los procesos de individualización del deseo. Siguiendo a Simondon, Stiegler afirma que durante el siglo XIX, la masificación de la producción industrial creó una proletarización del trabajador, es decir, una pérdida sistemática de su individualización (Stiegler, 2011b, p. 62). ${ }^{8}$ Sin embargo, durante el siglo

\footnotetext{
7 Para un análisis detallado de esta hipótesis véase Celis Bueno (2017).

8 Stiegler (2011b, p. 62) escribe: "Simondon analiza la proletarización del trabajo como una pérdida de la individualización, donde el trabajador, que una vez fue el individuo técnico, se convierte en el servidor de la máquina que lleva la herramienta, que se convierte a su vez en el nuevo individuo técnico". Esto implica una normalización
} 
$\mathrm{XX}$, el giro cognitivo del proceso productivo, la expansión de la industria cultural y la masificación de los objetos temporales industriales generaron una "nueva etapa de gramatización" en la que no solo el trabajador experimenta un proceso de proletarización, sino también el consumidor. Así como la industria moderna estandarizó el proceso de trabajo, de igual forma el post-fordismo está haciendo que los consumidores pierdan su "forma singular de estar en el mundo" (Stiegler, 2011b, p. 62). Esto conduce a una "pérdida planetaria de individuación, una generalización del proceso de proletarización a todos los modos de existencia y subsistencia" (Stiegler, 2011b, p. 63). Desde esta perspectiva, cuanto más avanza la industrialización de los objetos temporales, más se normaliza el deseo individual. Esto implica una tendencia autodestructiva característica del capitalismo, una pulsión de muerte intrínseca a la lógica de expansión capitalista (Stiegler, 2006, p. 40).

\section{Conclusiones}

El concepto de tiempo cinemático de Stiegler ofrece una alternativa para explorar la temporalidad de la economía de la atención más allá de la oposición fija entre el tiempo humano y el ciber-tiempo. Sin embargo, en su evaluación del capitalismo contemporáneo, Stiegler parece reintroducir ciertos juicios que reproducen un marco normativo $y$, por lo tanto, socavan el proyecto inmanente pretendido por su teoría de la tecnicidad originaria. En primer lugar, la crítica de Stiegler a la sociedad contemporánea parece caracterizarse por una aparente contradicción entre una "tecnofilia" (que enfatiza que no hay nada humano que no esté determinado técnicamente) y una "tecnofobia" propia de su diagnóstico político (Bradley, 2011, p. 135). Desde esta perspectiva, Stiegler parece valorizar un tiempo de la conciencia simple, homogéneo y ahistórico, por encima y en contra de la velocidad del tiempo híper-industrializado (Bradley, 2011, p. 135). Para Bradley, sin embargo, el trabajo de Stiegler no debe entenderse como una crítica de la industrialización de la temporalidad per se, sino como una crítica de la forma en que la industrialización de la temporalidad se convierte en la única forma de singularización en las sociedades contemporáneas (Bradley, 2011, p. 135). Bradley escribe que "la crítica de Stiegler al tiempo real refiere a su monopolización sobre los procesos de temporalización: el tiempo real no nos deja otra forma de temporalizar técnicamente el tiempo" (Bradley, 2011, p. 135). El problema, entonces, no sería la industrialización del tiempo en sí misma, sino el hecho de que la industrialización de la memoria "monopoliza tanto la producción como el consumo de la memoria terciaria actual y, con ella, la experiencia humana del tiempo" (Bradley, 2011, p. 135). La crítica de Stiegler a la industrialización de la temporalidad no debe verse como una crítica al aspecto técnico de la memoria desde la perspectiva de un tiempo natural no técnico, sino como una crítica al monopolio de una forma específica de tiempo. Esto significa que la pregunta política respecto a la industrialización del tiempo debiese ser “¿quién se apropia y quién controla hoy los procesos de individualización?” (Stiegler, 2006, p. 35).

En segundo lugar, parece haber una contradicción más significativa entre la teoría del tiempo de Stiegler y su crítica del capitalismo contemporáneo. Esta refiere a la confusión entre la comprensión inmanente de Stiegler de la noción de individuación y su crítica política del

del proceso laboral en el que cada trabajador individual pierde el conocimiento singular que definió su actividad, lo que lleva a una "pérdida de individualización” sistemática. 
capitalismo contemporáneo desde la perspectiva de la desindividuación. En su intento por desarrollar una teoría inmanente de la tecnología y el tiempo, Stiegler desarrolla una teoría presubjetiva de la individuación según la cual la constitución de cada singularidad depende de una superficie de inscripción que es externa a ella. Desde esta perspectiva, la individuación y el individuo se entienden como dos cosas completamente diferentes. Por el contrario, sin embargo, al desarrollar una crítica del capitalismo, Stiegler parece equiparar la individualización con la individualidad subjetiva, reproduciendo una definición metafísica del sujeto. Stiegler desarrolla su crítica del capitalismo postindustrial desde el punto de vista (externo) de la individualidad, argumentando que el deseo individual es corroído por la masificación de los objetos temporales industriales. En este sentido, su crítica repite el carácter individual de la subjetividad que caracteriza la economía política. Esto significa que Stiegler naturaliza el deseo individual como un punto de vista externo desde donde desarrollar una crítica del capitalismo contemporáneo, socavando así el proyecto inmanente al que apuntan sus conceptos de tiempo cinemático y tecnicidad originaria.

\section{Coda}

El texto hasta aquí presentado fue escrito en el año 2014 en el marco de la investigación doctoral "Towards an immanent critique of the atention economy: labour, time and power in post-fordist capitalism" y luego publicado como un capítulo del libro colectivo Memories of the Future: On Countervision (Peter Lang, 2017), editado por Stephen Wilson y Deborah Jaffé. Entretanto, una serie de progresos en el campo de las tecnologías de aprendizaje automático exigen reevaluar las tesis sobre tiempo cinemático y ciber-tiempo aquí planteadas. Por un lado, el actual desarrollo de tecnologías de automatización algorítmica acelera y profundiza las contradicciones aquí presentadas; por el otro, sin embargo, pareciese que estas transformaciones técnicas inauguran un nuevo marco de análisis donde dichas categorías comienzan a perder eficacia analítica. En relación a esto último, quisiera mencionar brevemente dos puntos.

En primer lugar, es posible afirmar que la producción de valor a través de las plataformas digitales ya no requiere necesariamente de la atención humana. La extracción de datos no ocurre de manera exclusiva a través de la captura de la atención de los individuos. Esta extracción se ha tornado tan transversal al modo de producción de estas plataformas que se realiza incluso en los momentos en los que nuestros ojos no están en relación a una pantalla (pensemos por ejemplo en la extracción de datos a través de la geolocalización, de los sensores en las "smart cities", etc.). Esto implica que, por un lado, la tesis de la economía de la atención parece intensificarse; por el otro, sin embargo, se amplía más allá de los límites de la atención humana y se torna "capitalismo de plataformas" (Snricek, 2018).

En segundo lugar, la producción de valor que se genera por esta extracción de datos comienza a depender más y más de algoritmos de aprendizaje automático. Esto desafía la primicia inicial de la tesis de la economía de la atención según la cual el exceso de información requeriría de un exceso de atención humana para ser procesada. El nuevo capitalismo de plataformas parece delegar en algoritmos de aprendizaje automático las tareas de procesamiento de información, transformando a los usuarios humanos en meras fuentes primarias de datos. De hecho, la traducción de este texto fue producida casi en su totalidad por un algoritmo de traducción automática entrenado por redes neuronales, con una incidencia mínima por parte de un agente humano. Este nuevo fenómeno pareciese que resolvería en favor del capital el conflicto entre la 
velocidad inhumana de los flujos de información y los límites físicos de la subjetividad humana identificado por Berardi (2014). El humano deja así de operar como medida del consumo de información, y comienza a aparecer simplemente como fuente de ésta. Más aún, estas tecnologías pueden identificar patrones al interior de dicha información de un modo que tiende a exceder a la capacidad humana para dar cuenta de ello. Esto produce un efecto de "cajanegrización" que acelera la tendencia según la cual el procesamiento de información es delegado a las máquinas y que torna al individuo en una mera fuente de información.

Como se mencionó, estos dos fenómenos implican reevaluar las tesis de la economía de la atención y del conflicto entre tiempo humano y tiempo de la información, incluso en la perspectiva de la "técnica originaria" abierta por Stiegler y desarrollada en este texto. El desarrollo de las nuevas tecnologías de extracción y procesamiento de datos exigiría, en mi parecer, salir del marco antropocéntrico en el cual ha permanecido la crítica de la economía política y arriesgar nuevos marcos categoriales desde donde pensar la producción de valor.

\section{Referencias}

Adorno, T., \& Horkheimer, M. (1998). Dialéctica de la ilustración. Madrid: Trotta.

Bazin, A. (1990). ¿Qué es el cine? Madrid: Ediciones Rialp.

Berardi, F. (2014). La Sublevación. Buenos Aires: Hekht Libros.

Bradley, A. (2011). Originary Technicity: The Theory of Technology from Marx to Derrida. Basingstoke: Palgrave Macmillan.

Buck-Morss, S. (1994). The cinema screen as prosthesis of perception: a historical account. In C. N. Seremetakis (Ed.), The Senses Still. Chicago: University of Chicago Press.

Casebier, A. (1991). Film and Phenomenology: Toward a Realist Theory of Cinematic Representation. Cambridge University Press.

Celis Bueno, C. (2017). The Attention Economy: Labour, Time, and Power in Cognitive Capitalism. London: Rowman \& Littlefield.

Crary, J. (2013). 24/7: Late Capitalism and the End of Sleep. New York: Verso.

Crogan, P. (2006). Essential Viewing. Film-Philosophy, 10, 2. http://www.filmphilosophy.com/2006v10n2/crogan.pdf

Doanne, M. A. (2016). La emergencia del tiempo cinemático. Madrid: Cendeac.

Hayles, K. (2007). Hyper and deep attention: The generational divide in cognitive modes. Profession, 187-199. https://www.jstor.org/stable/25595866

Marazzi, C. (2003). El sitio de los calcetines: el giro lingüístico de la economía y sus efectos sobre la política. Madrid: Akal.

Marx, K. (2009). Grundrisse II: Elementos fundamentales para la crítica de la economía politica (1857-1858). México: Siglo XXI.

Shaw, S. (2008). Film consciousness: from phenomenology to Deleuze. Chicago: University of Michigan Press.

Simon, H. A. (1971). Designing organizations for an information-rich world. In M. Greenberg (Ed.), Computers, Communication, and the Public Interest. Maryland: Johns Hopkins University Press. https:/ / digitalcollections.library.cmu.edu/awweb/awarchive?type=file\&item $=33748$

Sobchack, V. (1992). The address of the eye: a phenomenology of film experience. Princeton University Press. 
Srnicek, N. (2018) Capitalismo de plataformas. Buenos Aires: Caja negra.

Stiegler, B. (2004). La técnica y el tiempo 3: El tiempo del cine y la cuestión del malestar. Hondarribia: Hiru.

Stiegler, B. (2006). Anamnesis and Hypomnesis: The memories of desire. In A. Bradley \& L. Armand (Eds.), Technicity (pp. 15-41). Prague: Litteraria Pragensia.

Stiegler, B. (2011a). Suffocated Desire or how the Cultural Industry destroys the Individual: Contribution to a Theory of Mass Consumption. Parrhesia, 13, 52-61. http://xenopraxis.net/readings/stiegler_suffocateddesire.pdf

Stiegler, B. (2011b). The Decadence of Industrial Democracies (Vol. 1). Cambridge: Polity.

Stiegler, B. (2012). Relational Ecology and the Digital Pharmakon. Culture Machine, 13, 1-19. https://culturemachine.net/wp-content/uploads/2019/01/464-1026-1-PB.pdf 